\title{
Development and Validation of Diagnostic Economics Test for Secondary Schools
}

\author{
Lydia I. Eleje ${ }^{1, *}$, Nkechi P. M. Esomonu ${ }^{1}$, Ngozi N. Agu ${ }^{1}$, Romy O. Okoye ${ }^{1}$, Emma Obasi ${ }^{2}$ \& Frederick E. Onah ${ }^{3}$ \\ ${ }^{1}$ Department of Educational Foundations, Nnamdi Azikiwe University, Awka, Nigeria \\ ${ }^{2}$ Department of Social Science Education, Faculty of Education, Imo State University, Owerri, Nigeria \\ ${ }^{3}$ Department of Life Science Education, Imo State University, Owerri, Nigeria \\ *Correspondence: Department of Educational Foundations, Nnamdi Azikiwe University, Awka, Nigeria. Tel: \\ 234-803-275-6383. E-mail: ijeomaexcite@gmail.com
}

Received: May 3, 2016

doi:10.5430/wje.v6n3p90
Accepted: May 24, 2016 Online Published: June 19, 2016

URL: http://dx.doi.org/10.5430/wje.v6n3p90

\begin{abstract}
A diagnostic test in economics to aid the teachers determine student's specific weak content areas was developed and validated. Five research questions guided the study. Preliminary validation was done by two experienced teachers in the content area of secondary economics and two experts in test construction. The pilot testing was conducted for grammatical checking and compatibility bench marking while the test was try-out tested for item analysis. The overall number of test items was 83 . The test difficulty indices ranged from 0.24 to 0.79 and discrimination indices were within 0.22 to 0.65 . The content validity index for the 83 items was 0.76 and the Kappa statistic reliability value of the test was 0.83 . The test was found to be of good quality, valid and highly reliable. The test is therefore recommended for identifying specific mastered and least learned content areas in economics in Nigeria, South Africa and other countries with emerging economies.
\end{abstract}

Keywords: diagnostic test; difficulty indices; discrimination indices; distracter indices; economics; reliability; and validation

\section{Introduction}

Economics, a science concerned with how individuals, businessmen and governments make use of limited resources at their disposal (Chudi, 2013), plays a key role in the future progress of human kind. The contributions of economics have in no small measure been of immense benefit to the world in general. According to Chudi (2013), economics puts both leaders and citizens in a better position to understand economic problems and consequently proffer solutions to them. Economics as a subject is part of the senior secondary school (SSS) curriculum and it covers the basic aspects of human lives. The benefits of economics can only be realized if the students who are taught economics understand the basic concepts.

Despite the advantages of economics, there exist incessant failure of students in economics' examinations (Adu, Ojelabi \& Hammed, 2009). For example in Nigeria, available statistics from West African Examination Council (WAEC) Chief Examiners' reports (1999, 2001, 2003, 2004, 2006, 2007, 2008, 2011 and 2012) on senior secondary school students' achievement in economics revealed poor performance. In the report sheet, the chief examiners identified some problems that cause students' poor performance in economics including poor coverage of the syllabus, poor understanding of concepts taught, inability to draw and label demand curves properly, inaccurate measurement of diagram outlines and poor manipulations of demand equations. In 2010 and 2012, the chief examiners' reports also showed that students' weaknesses were generally observed to fall into two content areastheory of demand and theory of cost. Specifically the students' weaknesses were categorized as:

a) Calculations- majority of the students/candidates were unable to calculate total cost, marginal cost, price elasticity and quantity. A question in price elasticity of demand was attempted by very few candidates, in which they could not adequately calculate the price elasticity of demand.

b) Poor graph analysis- candidates attempted unsatisfactorily to draw graphs on demand curve. They poorly 
analyzed total and marginal cost diagrams.

Countries like South Africa, Ghana and Cote d'Ivoire have experienced similar trend (Fourie \& Krugell, 2015; Van der Berg \& Louw. 2006). In South Africa, students score at low levels in economics test even when compared with students in other African countries (Fourie \& Krugell. 2015; Van der Berg \& Louw, 2006). In a 2015 National senior certificate examination diagnostic report of South Africa, the general performance of students in economics declined from that of 2012 as indicated by $39.1 \%$ of candidates achieving $40 \%$ and above compared to $45.7 \%$ in 2012 (South African National Senior Certificate Examination, 2015). While some reasons for this poor performance may be evident, and there is widespread agreement that the main challenge in South Africa is the quality of education, there is little empirical analysis or diagnostic test that helps curriculum planers, policy makers and teachers, to identify students' specific mastered and least learned content areas in economics. So the availability of such test will help teachers to provide remedial help based on students' needs, thereby improving their performance. Thus, in South Africa, the diagnostic gap is also pressing. According to Fourie and Krugell (2015), the only recorded test for economics in South Africa is the Test of Understanding Economics in South Africa (TUESA), which paradoxically is not a diagnostic test.

Consequently, this study focused on the development and validation of diagnostic economics (theory of demand, theory of cost and market structure) test for secondary schools. These three content areas are mostly the calculative and graphical part of economics. In one of the WAEC Chief Examiner's report in 2012, it was suggested that the calculative part of economics is part of the subject that cannot be ignored. Candidates should realize this and subject themselves to practice before the examination. This will enable them to answer questions that may occur in this area appropriately.

Although, various researchers have developed diagnostic tests across different subjects in education like mathematics, language, music and science (Azizian and Abedi, 2006; Ceniza and Cereno, 2012; Chandrasegaran, Treagust and Mocerino, 2007; \& Ihekwaba, 2002), educational researchers have paid little attention to the development and validation of diagnostic tests in economics. In essence, the development and validation of a diagnostic economics test has not been researched on, thereby constituting an educational gap.

With regards to the use of diagnostic tests, different studies have found that the effective use of diagnostic tests improves teaching and learning, and students' performance (Betts, Hahn \& Zau, 2011; Kato, 2009; Patel, 2012; Richards, 2008). Thus, the development of diagnostic economics test will make such test available to economics teachers in secondary schools, which if used, will improve teaching and learning, as well as students' achievement in economics. The paucity of economics diagnostic tests to identify students' specific weak learning points in the content areas of economics necessitates this research.

The objective of this study therefore, is the development and validation of a diagnostic economics (theory of demand, theory of cost and market structure) test for secondary schools.

\subsection{Research Questions}

Based on the problem stated above, the study sought answers to the following research questions.

1. What are the difficulty indices of the diagnostic economics test (DET) items?

2. What are the discrimination indices of the DET items?

3. What are the distracter indices of the DET items?

4. How valid is the DET?

5. To what extent is the DET reliable?

\section{The Test Development Process}

The stages of diagnostic tests development were adapted from Alderson(2005), Ceniza and Cereno (2012) and Rivera (2007) resulting in several stages comprising (1) Planning the test (2) Constructing the test items (3) Initial validation of the test (4) Pilot testing (5) Trial testing (6) Item analysis(7) Determining the cut-off score and (8) Assembling of final test. The following describes each of the stages.

Planning the test: This section described the population, sample and sample technique, content and table of specifications.

The population of the study consisted of 6,495 senior secondary three (SS3) economics students in the 252 public secondary schools in Nigeria of the 2014/2015 academic session. 
The first sample for the test try-out consisted of 600 randomly selected students from 15 Nigerian' schools in different education zones. The schools were selected through disproportionate stratified random sampling while the students were selected through proportionate stratified random sampling. The second sample for establishing the reliability consisted of 100 students from 4 schools in Nigeria. These four schools volunteered to participate in the test re-tests study. Then from each of the four schools twenty five students were selected.

The content area of a diagnostic test, according to Alderson (2005), needed to be more specific and focused than that of a proficiency test. This was necessary, because a diagnostic test requires a detailed exhaustive analysis of the content area. The content area of this study covered theory of demand, theory of cost/revenue and market structure. These three topics were also the topics pointed out by the WAEC Chief Examiners' reports in 2010 and 2012 as the weak areas of students.

The table of specifications of the test consisted of 34, 25 and 24 items of theory of demand, theory of cost/revenue and market structure respectively. Various units of the test content were listed along the rows while different educational objectives to be tested were listed along the columns.

Table 1. The Diagnostic Economics Test Table of Specifications

\begin{tabular}{lccccc}
\hline Content & Know & Com & Appli & Interpr & Total \\
\hline Concept of demand & 4 & 2 & 4 & 4 & 14 \\
Elasticity of demand & 4 & 2 & 2 & 6 & 14 \\
Change in demand \& change in quantity demanded & 2 & 1 & 1 & 2 & 6 \\
Basic cost concepts & 2 & 3 & 8 & 2 & 15 \\
Opportunity \& money cost & 2 & 1 & 1 & 1 & 5 \\
Revenue concepts & 1 & 1 & 2 & 1 & 5 \\
Perfect market & 3 & 2 & 1 & 2 & 8 \\
Monopoly market & 3 & 2 & 1 & 3 & 9 \\
Other types of market & 2 & 2 & 1 & 2 & 7 \\
\hline Total & $\mathbf{2 3}$ & $\mathbf{1 6}$ & $\mathbf{2 1}$ & $\mathbf{2 3}$ & $\mathbf{8 3}$ \\
\hline
\end{tabular}

Abbreviations: Know=Knowledge; Com=Comprehension; Appli=Application; Interpr=Interpretation.

Constructing the test: An objective test with a multiple choice format was used in the construction of the DET because of its versatility in content coverage (Winarni, 2002). The researcher used two economics text books by the Ministry of Education (Anyaele, 2003; Anyanwuocha, 2006) in constructing 83 items in line with the table of specifications. The stems and options were provided/constructed following the guidelines stipulated by Alderson (2005) and Winarni, (2002).

Initial validation of the test: The initial draft of 83 items of the test was face and content validated by two experts in educational measurement and evaluation, and two experienced secondary school teachers of economics. These experts were requested to scrutinize the items (stems, options, keys and distracters) of the DET in terms of clarity, relevance, adequacy and comprehensiveness of the items. To guide the experts in the validation exercise, the topic of this study and table of specifications together with the draft test were given to the experts. After examining the test, they made some corrections on some of the items. Their expert observations, comments and suggestions were incorporated in the modifications of the test. The content validity was also ensured by computing the content validity index (CVI) of the DET.

Pilot testing: Pilot testing was necessary so as to ensure grammatical checking and compatibility bench marking of the DET items (Winarni, 2002).

In its preliminary form, the 83 items of the test were administered to 40 senior secondary three (SS3) economics students of a secondary school in Anambra State, in south-eastern Nigeria. The general impression of the students indicated low face validity due to omission of the answer (key) in two of the items, including more than one possible answer in an item and poor quality in the print-out of the test. Three students could not finish the last ten items due to fatigue of having to read and concentrate on three different content areas at a time (theory of demand, theory of cost/revenue and market structure).

The test items were modified by putting the omitted letters, words in the items affected and improving the quality of test print-out. The three modified items were included in the test to maintain 83 items so as not to omit any learning point as proposed by Alderson (2005). In order to overcome the problem of fatigue experienced by three students 
during the pilot testing, the test was subsequently arranged in three parts of content area to help the students concentrate on a single area of content at a time. This was an improvement/enhancement to the preliminary (pilot) version of the test, where the items were grouped according to objective levels.

The test try-out: The test try-out occurred during first term of 2014/2015 academic session when subject teachers and the students had completed the teaching and learning of the test content. Before the administration of the test try-out, the researcher made personal visits to secure permission from the concerned principals and economics subject teachers. The test was administered to $600 \mathrm{SS} 3$ economics students of the sampled schools. The test try-out was for the purpose of item analysis. That is, to distinguish the difficulty, discrimination and distracter indices of the test items.

The researcher, with the help of the economics teachers of the participating schools, administered the test to the students.

Item analysis: Item analysis was conducted on the test items mainly to ensure the quality of the items. It involved seven (7) main steps.

Step 1- Identify the higher and lower achievers. The total number of scripts collected and marked was (600). The students' marked scripts were arranged in the order of magnitude with respect to their scores. Then $33 \%$ of the scripts from the top and the same number of scripts from bottom were taken as the higher and lower achievers respectively (Author and Collaborator, 2010). The two groups were used in processing test responses.

Step 2- Process test responses. The researcher for each item, counted the number of students in each group who chose each alternative or omitted the item completely.

Step 3- Calculate item difficulty index. The difficulty index of each item was calculated using the formula.

$$
\frac{\mathrm{H}+\mathrm{L}}{2 \mathrm{~N}}
$$

Where,

$\mathrm{H}$ is the number of students in the higher achiever group who answered the item correctly.

$\mathrm{L}$ is the number of students in the lower group who answered the item correctly.

$\mathrm{N}$ is the total number of students in both the higher and lower groups.

Step 4- Calculate item discrimination index. The discrimination index of each item was calculated using the formula.

$$
\frac{\mathrm{H}-\mathrm{L}}{\mathrm{N}}
$$

Where, $\mathrm{H}, \mathrm{L}$ and $\mathrm{N}$ retain their meanings.

Step 5- Calculate the distracter indices. The distracter indices of each item were calculated using the formula.

$$
\frac{\mathrm{L}-\mathrm{H}}{\mathrm{N}}
$$

Where,

$\mathrm{H}$ represents those who failed the item in the higher group, $\mathrm{L}$ are those who failed the item in the lower group, and $\mathrm{N}$ is the total number of students in higher and lower group.

Step 6- Selection of good items. An item was considered good for inclusion in the final output of the test if it had difficulty index of 0.30 to 0.70 , discrimination index greater than 0.20 and a positive distracter index. However, items with appropriate difficulty indices but with discrimination indices of less than 0.20 were not accepted as good. Also items with appropriate discrimination index but have difficulty index of less than 0.20 or more than 0.80 were rejected (insert Table 2 around here). This according to Author and Collaborator (2010) is to ensure the content validity of the test.

Step 7- Revising and retesting of rejected items. To preserve the validity of the entire test and to maintain the total number of items all items that were rejected were revised or replaced. Revised or replaced items were re-administered to the target examinees (SS3 economics students), and its test responses were used to re-check the 
items' difficulty and discrimination indices for final verification of whether these items are to be retained or not.

Retesting of the revised and replaced items was necessary in preparation for the final version of the diagnostic test in order not to omit any learning point (Ceniza \& Cereno 2012; Izard 2005). The item difficulty and discrimination indices of the revised and retested items met the criteria for accepting item as good (see Table 3).

Determining the cut off score: In order to determine the bases of the cut-off score, the DET was given to three experienced teachers in economics to critically examine and determine the minimum number of items in the test a typical student should answer correctly before being classified as a master of the content. The first teacher suggested 60 items; the second teacher suggested 58 items while the third teacher suggested 56 items out of 83 items of the test. The average of 60,58 and 56 is 58 . The percentage of 58 out of 83 is 70 percent. Therefore, students who scored 70 percent of the DET correctly were classified as having mastered the content of the test. That is, 58 items out of the 83 items of the DET. Seventy percent (70\%) each of 34 items of theory of demand, 25 items of theory of cost/revenue and 24 items of market structure gave 24,17 and17 items respectively. Classification of students as masters or non-masters of the DET was necessary for the estimation of DET reliability (Onunkwo, 2002; Rivera, 2007).

Assembly of final test: The DET was arranged in three parts of content areas. The first part contains 34 items constructed from the content area of theory of demand. The second part contains 25 items from the content area of theory of cost/revenue, while the third part covers content area of market structure with 24 items.

\section{Validity of the test}

The test validity was ensured by computing the content validity index (CVI) of the DET. The final version of the DET was given to two content specialists on request to independently rate the relevance of each item to the type of content and behavior it purported to measure. The ratings were done in a four-point rating scale of Not Relevant $=1$, Somewhat Relevant $=2$, Quite Relevant $=3$, Very Relevant $=4$. The data yielded from these two raters were used to compute the inter-rater agreement statistics (i.e. Po, Pc and K).

Po measure the proportion of items classified in the same category by the two content specialists (i.e. proportion of observed agreement in their decisions) $=\underline{\mathrm{a}+\mathrm{d}}$

$$
a+b+c+d
$$

Pc asses the proportion of chance agreement $=$

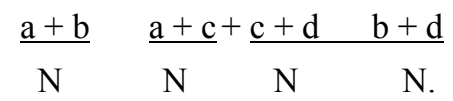

$\mathrm{K}$ measures the proportion of agreement uncontaminated by chance (i.e. Po corrected for chance agreement)

$=\frac{\mathrm{Po}-\mathrm{Pc}}{1-\mathrm{Pc}}$

The higher the value of CVI the more valid the test was.

\section{Test reliability}

Test-retest reliability measurements were employed in this study to ensure the temporal stability of the DET.

The final version of the test was administered twice to 100 SS3 economics students from four secondary schools in Anambra State that willingly volunteered to participate in the test re-test study (see Figure 1). Three weeks after the first administration of the test, a second administration with the same items was administered to the same 100 SS3 economics students for the purpose of comparing the proportions of the students who showed mastery of the content area being measured in the first and second administrations. A student was classified as a master of the content area of the test, when their score was equal to or above the cut off score (70\%). From the data obtained, po, pc, and $\mathrm{k}$ statistics were computed. The higher the value of $\mathrm{k}$, the more reliable the test was.

Proportion of observed agreement $(\mathrm{po})=\mathrm{a}+\mathrm{b}$.

Proportion of chance agreement $(p c)=(a+b)(a+c)+(c+d)(b+d)$.

Proportion of agreement uncontaminated by chance $(\mathrm{K})=\underline{\mathrm{Po}-\mathrm{Pc}}$

$$
1-\mathrm{Pc}
$$




\section{Results}

The results of the study were presented and analyzed below.

\section{Research question 1 and 2}

The difficulty and discrimination indices of the DET gotten after the item analysis of the test try-out are shown in Table 2.

Table 2. Summary Result of Difficulty and Discrimination Indices of the Test Try-Out

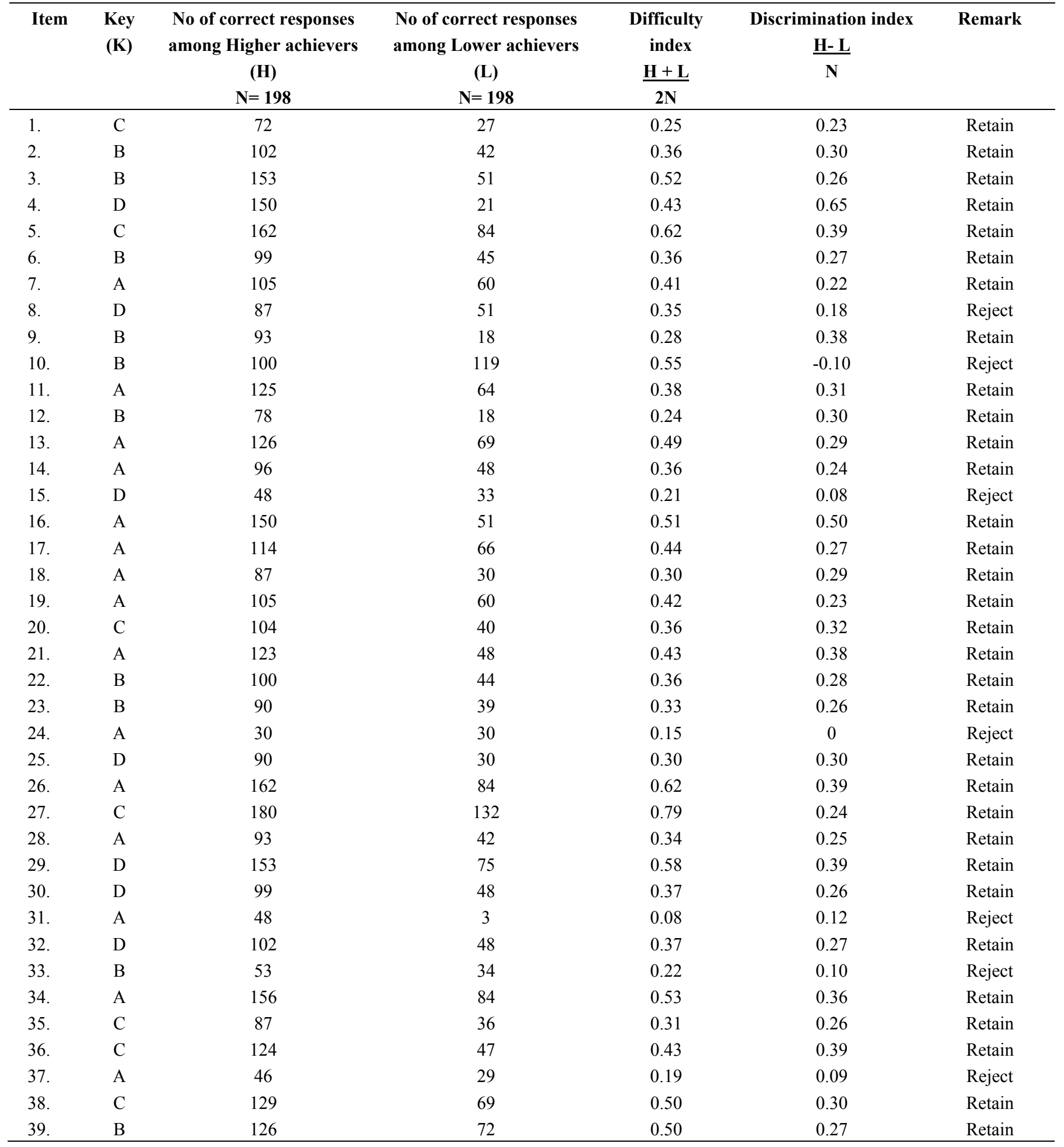




\begin{tabular}{|c|c|c|c|c|c|c|}
\hline 40. & $\mathrm{D}$ & 144 & 75 & 0.51 & 0.34 & Retain \\
\hline 41. & A & 78 & 30 & 0.27 & 0.24 & Retain \\
\hline 42. & B & 99 & 54 & 0.39 & 0.23 & Retain \\
\hline 43. & B & 57 & 45 & 0.26 & 0.06 & Reject \\
\hline 44. & D & 96 & 12 & 0.27 & 0.42 & Retain \\
\hline 45. & D & 102 & 33 & 0.34 & 0.35 & Retain \\
\hline 46. & B & 90 & 45 & 0.34 & 0.23 & Retain \\
\hline 47. & $\mathrm{C}$ & 105 & 51 & 0.39 & 0.27 & Retain \\
\hline 48. & $\mathrm{C}$ & 150 & 57 & 0.52 & 0.47 & Retain \\
\hline 49. & $\mathrm{C}$ & 132 & 66 & 0.50 & 0.33 & Retain \\
\hline 50. & C & 127 & 50 & 0.44 & 0.39 & Retain \\
\hline 51. & $\mathrm{C}$ & 138 & 45 & 0.46 & 0.47 & Retain \\
\hline 52. & $\mathrm{C}$ & 141 & 63 & 0.52 & 0.39 & Retain \\
\hline 53. & A & 139 & 89 & 0.58 & 0.25 & Retain \\
\hline 54. & A & 135 & 78 & 0.54 & 0.29 & Retain \\
\hline 55. & A & 87 & 33 & 0.30 & 0.27 & Retain \\
\hline 56. & B & 81 & 27 & 0.27 & 0.27 & Retain \\
\hline 57. & D & 105 & 45 & 0.38 & 0.30 & Retain \\
\hline 58. & $\mathrm{C}$ & 150 & 42 & 0.48 & 0.55 & Retain \\
\hline 59. & $\mathrm{C}$ & 108 & 48 & 0.39 & 0.30 & Retain \\
\hline 60. & $\mathrm{C}$ & 162 & 99 & 0.66 & 0.32 & Retain \\
\hline 61. & $\mathrm{C}$ & 114 & 57 & 0.43 & 0.29 & Retain \\
\hline 62. & $\mathrm{C}$ & 145 & 35 & 0.46 & 0.56 & Retain \\
\hline 63. & A & 132 & 75 & 0.52 & 0.29 & Retain \\
\hline 64. & D & 75 & 24 & 0.25 & 0.26 & Retain \\
\hline 65. & A & 51 & 48 & 0.25 & 0.02 & Reject \\
\hline 66. & A & 42 & 54 & 0.24 & -0.06 & Reject \\
\hline 67. & B & 105 & 57 & 0.41 & 0.24 & Retain \\
\hline 68. & A & 102 & 39 & 0.36 & 0.32 & Retain \\
\hline 69. & A & 96 & 48 & 0.36 & 0.24 & Retain \\
\hline 70. & $\mathrm{C}$ & 33 & 24 & 0.14 & 0.05 & Reject \\
\hline 71. & D & 90 & 42 & 033 & 0.24 & Retain \\
\hline 72. & B & 122 & 58 & 0.46 & 0.32 & Retain \\
\hline 73. & D & 114 & 57 & 0.43 & 0.29 & Retain \\
\hline 74. & $\mathrm{C}$ & 135 & 90 & 0.57 & 0.23 & Retain \\
\hline 75. & B & 150 & 72 & 0.56 & 0.39 & Retain \\
\hline 76. & D & 48 & 21 & 0.17 & 0.14 & Reject \\
\hline 77. & D & 39 & 21 & 0.15 & 0.09 & Reject \\
\hline 78. & A & 129 & 69 & 0.50 & 0.38 & Retain \\
\hline 79. & C & 118 & 61 & 0.45 & 0.29 & Retain \\
\hline 80. & $\mathrm{C}$ & 156 & 78 & 0.59 & 0.39 & Retain \\
\hline 81. & B & 87 & 60 & 0.37 & 0.14 & Reject \\
\hline 82. & A & 97 & 38 & 0.34 & 0.30 & Retain \\
\hline 83. & $\mathrm{~A}$ & 72 & 37 & 0.40 & -0.08 & Reject \\
\hline
\end{tabular}

The difficulty and discrimination indices for each item suggested that sixty eight (68) items be retained while item numbers $8,10,15,24,31,33,37,43,65,66,70,76,77,81$ and 83 be rejected. The rejected items were either revised or replaced and re-tested.

Table 3 shows the item difficulty and discrimination results after retesting of the revised and replaced items. 
Table 3. Difficulty and Discrimination Indices of the 15 Retested Items

\begin{tabular}{|c|c|c|c|c|c|c|}
\hline Item & $\begin{array}{l}\text { Key } \\
\text { (K) }\end{array}$ & $\begin{array}{c}\text { No of correct responses } \\
\text { among Higher achievers } \\
\left(\begin{array}{c}\text { H) } \\
\mathrm{N}=198\end{array}\right. \\
\end{array}$ & $\begin{array}{c}\text { No of correct responses } \\
\text { among Lower achievers } \\
\text { (L) } \\
\mathrm{N}=198 \\
\end{array}$ & $\begin{array}{c}\text { Difficulty } \\
\text { index } \\
\frac{H+L}{2 N}\end{array}$ & $\begin{array}{l}\text { Discriminatio } \\
n \text { index } \\
\frac{H-L}{N}\end{array}$ & Remark \\
\hline 8 & $\mathrm{D}$ & 119 & 13 & 0.33 & 0.54 & Retain \\
\hline 10 & $\mathrm{~B}$ & 138 & 66 & 0.52 & 0.36 & Retain \\
\hline 15 & $\mathrm{D}$ & 139 & 33 & 0.43 & 0.54 & Retain \\
\hline 24 & $\mathrm{~A}$ & 146 & 33 & 0.45 & 0.57 & Retain \\
\hline 31 & A & 93 & 39 & 0.33 & 0.27 & Retain \\
\hline 33 & $\mathrm{~B}$ & 118 & 4 & 0.31 & 0.58 & Retain \\
\hline 37 & A & 145 & 41 & 0.46 & 0.53 & Retain \\
\hline 43 & $\mathrm{~B}$ & 138 & 39 & 0.45 & 0.50 & Retain \\
\hline 65 & A & 132 & 26 & 0.40 & 0.54 & Retain \\
\hline 66 & A & 145 & 19 & 0.41 & 0.64 & Retain \\
\hline 70 & $\mathrm{C}$ & 118 & 19 & 0.35 & 0.50 & Retain \\
\hline 76 & $\mathrm{D}$ & 125 & 67 & 0.48 & 0.29 & Retain \\
\hline 77 & $\mathrm{D}$ & 125 & 59 & 0.46 & 0.33 & Retain \\
\hline 81 & B & 152 & 46 & 0.50 & 0.54 & Retain \\
\hline 83 & A & 145 & 33 & 0.45 & 0.57 & Retain \\
\hline
\end{tabular}

Research question 3

The distracter indices of the DET obtained after item analysis are presented in Table 4.

Table 4. Summary Table of Distracter Indices of DET Final Version

\begin{tabular}{|c|c|c|c|c|c|c|c|c|c|c|c|c|c|c|c|}
\hline \multirow[t]{2}{*}{$\begin{array}{c}\text { ITEM } \\
\text { NO }\end{array}$} & \multicolumn{2}{|c|}{$\begin{array}{c}\text { NO OF } \\
\text { RESPONDENT } \\
\text { S WHO } \\
\text { CHOOSE } \\
\text { OPTION A }\end{array}$} & \multicolumn{2}{|c|}{$\begin{array}{c}\text { NO OF } \\
\text { RESPOND } \\
\text { ENTS } \\
\text { WHO } \\
\text { CHOOSE } \\
\text { OPTION B }\end{array}$} & \multicolumn{2}{|c|}{$\begin{array}{c}\text { NO OF } \\
\text { RESPOND } \\
\text { ENTS } \\
\text { WHO } \\
\text { CHOOSE } \\
\text { OPTION C }\end{array}$} & \multicolumn{2}{|c|}{$\begin{array}{c}\text { NO OF } \\
\text { RESPOND } \\
\text { ENTS } \\
\text { WHO } \\
\text { CHOOSE } \\
\text { OPTION D }\end{array}$} & \multirow[t]{2}{*}{$\begin{array}{c}\text { OM } \\
\text { IT }\end{array}$} & \multirow[t]{2}{*}{$\begin{array}{c}\text { TOTA } \\
\quad \mathbf{L}\end{array}$} & \multicolumn{4}{|c|}{$\begin{array}{l}\text { DISTRACTIBILITY INDEX (DI) } \\
\qquad \begin{array}{c}\underline{\mathrm{L}-\mathrm{H}} \\
\mathrm{N} \\
\mathrm{N}=\underline{\underline{198}}\end{array}\end{array}$} & \multirow[t]{2}{*}{ REMARK } \\
\hline & $\mathbf{L}$ & $\mathbf{H}$ & $\mathbf{L}$ & H & $\mathbf{L}$ & H & $\mathbf{L}$ & H & & & $\mathbf{A}$ & B & C & D & \\
\hline 1. & 30 & 15 & 9 & 6 & 27 & 72 & 129 & 99 & 9 & 396 & 0.08 & 0.02 & $\mathrm{~K}$ & 0.15 & Distracters are ok \\
\hline 2. & 69 & 45 & 42 & 102 & 33 & 12 & 54 & 39 & - & 396 & 0.12 & $\mathrm{~K}$ & 0.11 & 0.08 & Distracters are ok \\
\hline 3. & 60 & 9 & 51 & 153 & 18 & 9 & 69 & 27 & - & 396 & 0.26 & $\mathrm{~K}$ & 0.05 & 0.21 & Distracters are ok \\
\hline 4. & 54 & 24 & 69 & 18 & 48 & 6 & 21 & 150 & 6 & 396 & 0.15 & 0.26 & 0.18 & $\mathrm{~K}$ & Distracters are ok \\
\hline 5. & 60 & 15 & 30 & 15 & 84 & 162 & 24 & 6 & - & 396 & 0.23 & 0.08 & $\mathrm{~K}$ & 0.09 & Distracters are ok \\
\hline 6. & 30 & 24 & 45 & 99 & 21 & 15 & 102 & 60 & - & 396 & 0.03 & $\mathrm{~K}$ & 0.03 & 0.21 & Distracters are ok \\
\hline 7. & 60 & 105 & 33 & 15 & 45 & 24 & 57 & 51 & 6 & 396 & $\mathrm{~K}$ & 0.09 & 0.11 & 0.03 & Distracters are ok \\
\hline 8. & 59 & 19 & 66 & 40 & 60 & 20 & 13 & 119 & - & 396 & 0.20 & 0.13 & 0.10 & $\mathrm{~K}$ & Distracters are ok \\
\hline 9. & 57 & 45 & 18 & 93 & 87 & 42 & 27 & 15 & 12 & 396 & 0.06 & K & 0.23 & 0.06 & Distracters are ok \\
\hline 10. & 40 & 27 & 66 & 138 & 33 & 14 & 59 & 19 & - & 396 & 0.07 & $\mathrm{~K}$ & 0.10 & 0.20 & Distracters are ok \\
\hline 11. & 64 & 125 & 62 & 10 & 48 & 39 & 18 & 21 & 9 & 396 & $\mathrm{~K}$ & 0.26 & 0.05 & 0.02 & Distracters are ok \\
\hline 12. & 63 & 42 & 18 & 78 & 63 & 33 & 54 & 45 & - & 396 & 0.11 & $\mathrm{~K}$ & 0.15 & 0.05 & Distracters are ok \\
\hline 13. & 69 & 126 & 78 & 54 & 27 & 9 & 24 & 9 & - & 396 & $\mathrm{~K}$ & 0.12 & 0.09 & 0.07 & Distracters are ok \\
\hline 14. & 48 & 96 & 57 & 33 & 51 & 39 & 39 & 30 & 3 & 396 & K & 0.12 & 0.06 & 0.05 & Distracters are ok \\
\hline 15. & 46 & 13 & 60 & 26 & 59 & 20 & 33 & 139 & - & 396 & 0.17 & 0.17 & 0.20 & $\mathrm{~K}$ & Distracters are ok \\
\hline 16. & 51 & 150 & 54 & 24 & 51 & 21 & 36 & 0 & 9 & 396 & $\mathrm{~K}$ & 0.15 & 0.15 & 0.18 & Distracters are ok \\
\hline 17. & 66 & 114 & 42 & 36 & 51 & 30 & 27 & 15 & 15 & 396 & $\mathrm{~K}$ & 0.06 & 0.11 & 0.06 & Distracters are ok \\
\hline 18. & 30 & 87 & 39 & 39 & 69 & 48 & 54 & 18 & 12 & 396 & $\mathrm{~K}$ & 0 & 0.11 & 0.18 & B Replace \\
\hline 19. & 60 & 105 & 39 & 30 & 45 & 24 & 48 & 30 & 15 & 396 & K & 0.05 & 0.11 & 0.09 & Distracters are ok \\
\hline 20. & 54 & 48 & 63 & 21 & 40 & 104 & 29 & 19 & 18 & 396 & 0.03 & 0.21 & $\mathrm{~K}$ & 0.05 & Distracters are ok \\
\hline 21. & 48 & 123 & 51 & 21 & 51 & 33 & 33 & 15 & 21 & 396 & $\mathrm{~K}$ & 0.15 & 0.09 & 0.09 & Distracters are ok \\
\hline 22. & 64 & 38 & 44 & 100 & 48 & 33 & 30 & 18 & 21 & 396 & 0.13 & $\mathrm{~K}$ & 0.08 & 0.06 & Distracters are ok \\
\hline 23. & 60 & 48 & 39 & 90 & 42 & 30 & 45 & 24 & 18 & 396 & 0.06 & $\mathrm{~K}$ & 0.06 & 0.11 & Distracters are ok \\
\hline 24. & 33 & 146 & 80 & 33 & 46 & 6 & 39 & 13 & - & 396 & $\mathrm{~K}$ & 0.24 & 0.20 & 0.13 & Distracters are ok \\
\hline
\end{tabular}




\begin{tabular}{|c|c|c|c|c|c|c|c|c|c|c|c|c|c|c|c|}
\hline 25. & 54 & 21 & 24 & 39 & 84 & 45 & 30 & 90 & 9 & 396 & 0.17 & -0.08 & 0.20 & $\mathrm{~K}$ & B Revise \\
\hline 26. & 84 & 162 & 24 & 6 & 78 & 21 & 12 & 6 & 3 & 396 & $\mathrm{~K}$ & 0.09 & 0.29 & 0.03 & Distracters are ok \\
\hline 27. & 27 & 15 & 6 & 0 & 132 & 180 & 33 & 3 & - & 396 & 0.06 & 0.03 & $\mathrm{~K}$ & 0.15 & Distracters are ok \\
\hline 28. & 42 & 93 & 66 & 60 & 75 & 42 & 15 & 3 & - & 396 & $\mathrm{~K}$ & 0.03 & 0.17 & 0.06 & Distracters are ok \\
\hline 29. & 18 & 3 & 39 & 12 & 63 & 30 & 75 & 153 & 3 & 396 & 0.08 & 0.14 & 0.17 & $\mathrm{~K}$ & Distracters are ok \\
\hline 30. & 42 & 24 & 57 & 42 & 51 & 33 & 48 & 99 & - & 396 & 0.09 & 0.08 & 0.09 & $\mathrm{~K}$ & Distracters are ok \\
\hline 31. & 39 & 93 & 138 & 52 & 39 & 33 & 61 & 20 & - & 396 & $\mathrm{~K}$ & 0.43 & 0.03 & 0.21 & Distracters are ok \\
\hline 32. & 21 & 15 & 51 & 45 & 78 & 30 & 48 & 102 & 6 & 396 & 0.03 & 0.03 & 0.03 & $\mathrm{~K}$ & Distracters are ok \\
\hline 33. & 77 & 21 & 4 & 118 & 38 & 19 & 79 & 40 & - & 396 & 0.28 & $\mathrm{~K}$ & 0.10 & 0.20 & Distracters are ok \\
\hline 34. & 84 & 156 & 18 & 0 & 27 & 18 & 69 & 24 & - & 396 & $\mathrm{~K}$ & 0.09 & 0.05 & 0.23 & Distracter are ok \\
\hline 35. & 96 & 87 & 42 & 15 & 36 & 87 & 21 & 9 & 3 & 396 & 0.05 & 0.14 & $\mathrm{~K}$ & 0.06 & Distracters are ok \\
\hline 36. & 69 & 42 & 27 & 12 & 45 & 126 & 51 & 18 & 6 & 396 & 0.14 & 0.08 & K & 0.17 & Distracters are ok \\
\hline 37. & 41 & 145 & 46 & 20 & 72 & 20 & 39 & 13 & - & 396 & $\mathrm{~K}$ & 0.13 & 0.26 & 0.13 & Distracters are ok \\
\hline 38. & 51 & 15 & 39 & 30 & 69 & 129 & 36 & 24 & 3 & 396 & 0.18 & 0.05 & $\mathrm{~K}$ & 0.06 & Distracter are ok \\
\hline 39. & 69 & 511 & 72 & 126 & 33 & 15 & 21 & 6 & 3 & 396 & 0.09 & $\mathrm{~K}$ & 0.09 & 0.08 & Distracters are ok \\
\hline 40. & 87 & 27 & 24 & 18 & 12 & 9 & 75 & 144 & - & 396 & 0.30 & 0.03 & 0.02 & $\mathrm{~K}$ & Distracters are ok \\
\hline 41. & 30 & 78 & 33 & 30 & 81 & 30 & 54 & 51 & 9 & 396 & $\mathrm{~K}$ & 0.02 & 0.3 & 0.02 & Distracters are ok \\
\hline 42. & 21 & 24 & 54 & 99 & 60 & 30 & 60 & 42 & 6 & 396 & -0.02 & $\mathrm{~K}$ & 0.5 & 0.09 & A Replace \\
\hline 43. & 79 & 19 & 39 & 138 & 46 & 15 & 33 & 26 & - & 396 & 0.30 & K & 0.16 & 0.04 & Distracters are ok \\
\hline 44. & 72 & 15 & 57 & 57 & 57 & 27 & 12 & 96 & 3 & 396 & 0.29 & 0 & 0.15 & $\mathrm{~K}$ & B Revise \\
\hline 45. & 45 & 30 & 30 & 27 & 84 & 39 & 33 & 102 & 6 & 396 & 0.08 & 0.02 & 0.23 & K & Distracters are ok \\
\hline 46. & 54 & 39 & 45 & 90 & 72 & 45 & 27 & 9 & 15 & 396 & 0.08 & $\mathrm{~K}$ & 0.14 & 0.09 & Distracters are ok \\
\hline 47. & 45 & 27 & 84 & 42 & 51 & 105 & 12 & 21 & 9 & 396 & 0.09 & 0.21 & $\mathrm{~K}$ & 0.05 & Distracters are ok \\
\hline 48. & 48 & 9 & 63 & 30 & 57 & 150 & 24 & 6 & 9 & 396 & 0.20 & 0.17 & K & 0.09 & Distracters are ok \\
\hline 49. & 30 & 6 & 63 & 45 & 66 & 132 & 33 & 12 & 9 & 396 & 0.12 & 0.09 & K & 0.11 & Distracters are ok \\
\hline 50. & 60 & 33 & 58 & 20 & 50 & 127 & 27 & 15 & 6 & 396 & 0.14 & 0.19 & K & 0.06 & Distracters are ok \\
\hline 51. & 51 & 33 & 54 & 12 & 45 & 138 & 45 & 12 & 6 & 396 & $0 . .09$ & 0.21 & $\mathrm{~K}$ & 0.17 & A Replace \\
\hline 52. & 63 & 36 & 27 & 3 & 63 & 141 & 42 & 15 & 6 & 396 & 0.14 & 0.12 & $\mathrm{~K}$ & 0.14 & Distracters are ok \\
\hline 53. & 89 & 139 & 42 & 30 & 43 & 23 & 24 & 3 & 3 & 396 & $\mathrm{~K}$ & 0.10 & 0.09 & 0.11 & Distracters are ok \\
\hline 54. & 78 & 135 & 60 & 12 & 24 & 6 & 36 & 42 & 3 & 396 & $\mathrm{~K}$ & 0.21 & 0.09 & -0.03 & D Replace \\
\hline 55. & 33 & 87 & 63 & 30 & 36 & 42 & 66 & 36 & 3 & 396 & $\mathrm{~K}$ & 0.17 & -0.03 & 0.15 & C Replace \\
\hline 56. & 60 & 48 & 27 & 81 & 51 & 30 & 57 & 30 & 12 & 396 & 0.06 & $\mathrm{~K}$ & 0.11 & 0.14 & Distracters are ok \\
\hline 57. & 42 & 24 & 60 & 24 & 51 & 36 & 45 & 105 & 9 & 396 & 0.09 & 0.18 & 0.08 & K & Distracters are ok \\
\hline 58. & 66 & 18 & 45 & 21 & 42 & 150 & 42 & 9 & 3 & 396 & 0.24 & 0.12 & $\mathrm{~K}$ & 0.17 & Distracters are ok \\
\hline 59. & 81 & 42 & 21 & 18 & 48 & 108 & 45 & 24 & 9 & 396 & 0.20 & 0.02 & $\mathrm{~K}$ & 0.11 & Distracters are ok \\
\hline 60. & 15 & 3 & 24 & 6 & 99 & 162 & 60 & 21 & 6 & 396 & 0.06 & 0.09 & $\mathrm{~K}$ & 0.20 & Distracters are ok \\
\hline 61. & 81 & 57 & 33 & 18 & 57 & 114 & 24 & 3 & 9 & 396 & 0.12 & 0.08 & K & 0.11 & Distracters are ok \\
\hline 62. & 66 & 15 & 61 & 20 & 35 & 145 & 36 & 15 & 3 & 396 & 0.26 & 0.21 & $\mathrm{~K}$ & 0.11 & Distracters are ok \\
\hline 63. & 75 & 132 & 12 & 6 & 60 & 39 & 51 & 12 & 9 & 396 & $\mathrm{~K}$ & 0.03 & 0.11 & 0.20 & Distracters are ok \\
\hline 64. & 51 & 72 & 90 & 18 & 30 & 30 & 24 & 75 & 3 & 396 & 0.11 & 0.36 & -0.02 & $\mathrm{~K}$ & C Replace \\
\hline 65. & 26 & 132 & 40 & 19 & 92 & 39 & 40 & 8 & - & 396 & $\mathrm{~K}$ & 0.10 & 0.27 & 0.16 & Distracters are ok \\
\hline 66. & 19 & 145 & 39 & 21 & 60 & 13 & 80 & 19 & - & 396 & $\mathrm{~K}$ & 0.09 & 0.24 & 0.24 & Distracters are ok \\
\hline 67. & 78 & 60 & 57 & 105 & 33 & 30 & 27 & 3 & 3 & 396 & 0.09 & $\mathrm{~K}$ & 0.02 & 0.12 & Distracters are $\mathrm{Ok}$ \\
\hline 68. & 39 & 102 & 54 & 36 & 78 & 39 & 27 & 18 & 3 & 396 & $\mathrm{~K}$ & 0.09 & 0.20 & 0.05 & Distracters are ok \\
\hline 69. & 48 & 96 & 60 & 30 & 66 & 60 & 24 & 9 & 3 & 396 & $\mathrm{~K}$ & 0.03 & 0.03 & 0.08 & Distracters are ok \\
\hline 70. & 46 & 21 & 52 & 20 & 19 & 118 & 81 & 39 & - & 396 & 0.13 & 0.16 & $\mathrm{~K}$ & 0.21 & Distracters are ok \\
\hline 71. & 78 & 57 & 27 & 30 & 51 & 18 & 42 & 90 & 3 & 396 & 0.11 & -0.02 & 0.17 & $\mathrm{~K}$ & B Revise \\
\hline 72. & 45 & 12 & 58 & 122 & 50 & 37 & 42 & 27 & 3 & 396 & 0.17 & $\mathrm{~K}$ & 0.07 & 0.08 & Distracters are $\mathrm{Ok}$ \\
\hline 73. & 60 & 51 & 21 & 15 & 57 & 18 & 57 & 114 & 3 & 396 & 0.05 & 0.03 & 0.20 & $\mathrm{~K}$ & Distracters are ok \\
\hline 74. & 48 & 6 & 24 & 21 & 90 & 135 & 27 & 21 & 24 & 396 & 0.21 & 0.02 & $\mathrm{~K}$ & 0.03 & Distracters are ok \\
\hline 75. & 78 & 27 & 72 & 150 & 36 & 12 & 9 & 3 & 9 & 396 & 0.26 & $\mathrm{~K}$ & 0.12 & 0.03 & Distracters are ok \\
\hline 76. & 60 & 52 & 52 & 14 & 19 & 7 & 67 & 125 & - & 396 & 0.04 & 0.19 & 0.06 & $\mathrm{~K}$ & Distracters are ok \\
\hline 77. & 52 & 39 & 59 & 15 & 28 & 19 & 59 & 125 & - & 396 & 0.07 & 0.22 & 0.05 & $\mathrm{~K}$ & Distracters are ok \\
\hline 78. & 69 & 129 & 36 & 24 & 51 & 30 & 36 & 9 & 12 & 396 & $\mathrm{~K}$ & 0.09 & 0.11 & 0.14 & Distracters are ok \\
\hline 79. & 35 & 10 & 45 & 30 & 61 & 116 & 54 & 30 & 15 & 396 & 0.13 & 0.08 & $\mathrm{~K}$ & 0.12 & Distracters are ok \\
\hline 80. & 63 & 21 & 39 & 12 & 78 & 156 & 15 & 3 & 9 & 396 & 0.21 & 0.14 & $\mathrm{~K}$ & 0.06 & Distracters are ok \\
\hline 81. & 74 & 19 & 46 & 152 & 52 & 20 & 26 & 7 & - & 396 & 0.28 & $\mathrm{~K}$ & 0.16 & 0.10 & Distracters are ok \\
\hline 82. & 38 & 97 & 21 & 24 & 55 & 50 & 81 & 21 & 9 & 396 & $\mathrm{~K}$ & -0.02 & 0.03 & 0.09 & B Revise \\
\hline 83. & 33 & 145 & 66 & 13 & 60 & 19 & 39 & 21 & - & 396 & $\mathrm{~K}$ & 0.27 & 0.21 & 0.09 & Distracters are ok \\
\hline
\end{tabular}




\section{Research question 4}

Content validity index (CVI) of the DET was computed to determine the validity of the DET. The inter-rater agreement and content validity index of the DET were computed and presented in Table 5.

Table 5. Summary of Inter-Rater Agreements

\begin{tabular}{lc}
\hline Inter-rater dimensions & Inter-rater agreement \\
\hline Proportion of observed agreement in their decision $(\mathrm{Po})$ & 0.82 \\
Proportion of chance agreement $(\mathrm{Pc})$ & 0.73 \\
Proportion of agreement uncontaminated by chance $(\mathrm{K})$ & 0.34 \\
Content Validity Index (CVI) & 0.76 \\
\hline
\end{tabular}

As observed in the summary results in Table 5, CVI of DET is 0.7590 . This is the content validity index (CVI).

\section{Research question 5}

The reliability value for the three topics (Theory of Demand, Theory of Cost/Revenue and Market Structure) were computed separately and presented in Table 6.

Table 6. Summary Results of DET Po, Pc and K Statistics

\begin{tabular}{lcccc}
\hline & Theory of Demand & $\begin{array}{c}\text { Theory of } \\
\text { Cost/Revenue }\end{array}$ & Market Structure & DET \\
\hline Po & 0.86 & 0.86 & 0.90 & 0.94 \\
Pc & 0.62 & 0.65 & 0.59 & 0.64 \\
K & 0.72 & 0.60 & 0.76 & 0.83 \\
\hline
\end{tabular}

As observed in the summary results in Table 6, the reliability value for section A (theory of demand) of the test was 0.72 , the reliability for section B (theory of cost/revenue) was 0.60 and the reliability for section $\mathrm{C}$ (market structure) was 0.76 . The single $\mathrm{K}$ value for the DET was 0.83 . This was the Kappa statistics (k) reliability value.

\section{Discussion}

The economic events and economic issues remain a significant burden worldwide. This is because the leading economies are facing debt crises, recessions and downturns in the growth of the economies. The exchange rate for foreign exchange are constantly fluctuating. Consumers are confronted on a daily basis with the rising food prices and fluctuating oil prices. But despite the attention that has been given to economics in the recent years, the overwhelming findings remain that students are unfamiliar with economics and basic economic concepts (Fourie \& Krugell, 2015). Fourie and Krugell (2015) and Chudi (2013) posit that if the students are familiar with the basic concepts of economics, it may directly affect positively in improving the economy. A dire challenge faced by Nigeria, South Africa and many other countries with emerging economies is the economics teachers' lack of diagnostic test to aid the teacher in identifying students' specific least learned content areas of economic concepts. The discourse about the potential solution to this issue revolve around diagnostic test.

\subsection{Item Difficulty and Discrimination Indices of the DET}

As observed in Table 2, 68 item were found to be good with appropriate difficulty and discrimination indices. Items numbers $24,31,37,70,76$ and 77 had difficulty indices that were less than 0.20 . This means that they were very difficult items. No item in the current study was found to be very easy.

Table 2 also shows that, three $(10,66,83)$ items had negative discrimination indices. This indicated that low ability students performed better on those items than high ability students as previously described by Author and collaborator (2010). Such items discriminated but in the negative (wrong) direction. Item number 24 had a zero (0.0) discrimination index. This implied that equal number of students in the high ability group and low ability group correctly answered the items. Such items did not discriminate. On the other hand, 11 items $(8,15,31,33,37,43,65$, $70,76,77$ and 81$)$ as seen in a study by Onunkwo (2002). This study in Nigeria, had low but positive discrimination values $(0.0 \leq 0.20)$. This implied that students who incorrectly answered these items also scored high on the test 
overall, while students who correctly answered the items scored low on the test overall as suggestions.

Similarly in South Africa, the quality of candidates' performance in economics is disappointing when compared to previous years. It does appear that the 2015 NSC diagnostic report for economics was considered to help the candidates in general and the weaker learners especially to take advantage of the low difficulty questions that comprised of about 30\% of the questions (South African National Senior Certificate Examination 2015).

Items that had poor difficulty and discrimination indices were retested. This retesting process was to ensure that no learning points were omitted in the final version of DET as suggested by Ceniza and Cereno (2012).

\subsection{Distracter Indices of the DET}

The distracters of the items after the test try-out revealed that 59 items have 3 positive distracter values, 19 items had 2 positive distracter values and 5 items had only one positive distractibility index. The positive value indicated that the distracters are good. It also implied that more of the students in the low ability group chose the distracter than those in the high ability group. It was also observed in Table 4 that some distracter indices were either negative or zero. The negative value of the indices indicated that the distracters were bad or poor. This showed that they were chosen by more of the students in the high ability group than those in the low ability group. The zero distracter indices revealed that these distracters did not distract or confuse any student. This means that, the distracters with zero values made no differentiation in the amount of confusion it posed to student in the two ability groups. The distracters with negative or zero values were reviewed then replaced for improvement and ease of the test takers. Other items were also improved by restructuring the manner of questioning to lesson confusions in answering.

\subsection{Validity of the DET}

Validity of the test was done by matching the test items from the objectives and presenting the whole test to two experts in the test construction and two experienced teachers in the content areas of secondary economics for item review. These experts guaranteed that the instrument had strong content validity in which each item represented the content area being investigated, rather than asking unrelated questions.

According to findings of this study, in Table 5, the values of Po and $\mathrm{K}$ were 0.8193 and 0.3361 respectively. This indicated that the type of content and component behaviors of the test were clearly stated, there was no need for refinement and the raters understood the rating scale. Also from Table 5, the content validity index of test was 0.7590 . This implied that $75.90 \%$ of the test items were rated Quite Relevant or Very Relevant (i.e. 3 or 4 ) to the type of content and behaviors being measured, by the two content specialists. This implied that the test was valid.

\subsection{Reliability of the DET}

As observed in the summary results in Table 6 , the proportion of agreement uncontaminated by chance $(\mathrm{k})$ for theory of demand, theory of cost/revenue and market structure were $0.63,0.60$ and 0.76 respectively. The single/general $\mathrm{k}$ value was 0.83 . This implied that $83 \%$ of the observed agreements in the decisions made by the two administrations of the test were uncontaminated by chance. That is, there was $83 \%$ certainty of the consistency of the test in classifying students into mastery states. This implied that the test was very reliable. A previous study on reliability by Ceniza and Cereno (2012), came to a similar conclusion. According to Ceniza and Cereno (2012), the reliability coefficient within the range of 0.81 to 1.0 indicated high reliability, 0.61 to 0.80 signified a moderate reliability, 0.41 to 0.60 signified fair reliability, 0.10 to 0.40 signified slight reliability, and less than 0.10 signified no reliability. Therefore, the test reliability was high.

This study provides valuable useful findings in the field of economics education, since it is the first conceptual diagnostic test in economics in Africa, to the best of our knowledge. However, some limitations are attributed to this study. First, the level of performance of the students was low, and it was possible that more studious students would have performed differently. Second, the study did not have any control group, because the researcher could not access group with similar characteristics.

\section{Conclusions}

The results of this study reflect that the diagnostic test being developed is valid. The final output of the test showed that the overall test difficulty was within the range of 0.24 to 0.79 . As demonstrated from findings in this study and according to Ceniza and Cereno (2012), the diagnostic test therefore has a moderate level of difficulty. The discrimination indices were within the range of 0.22 to 0.65 . This according to Winarni (2002) implies a moderately discriminating instrument. With the CVI at 0.7590, the developed diagnostic economics test (DET) shows good validity. Also, the $\mathrm{K}$ values at $0.63,0.60,0.76$ and a general reliability of 0.83 , indicate that the currently developed 
diagnostic economics test (DET) indicates high reliability. Thus, it could be concluded that the diagnostic test developed in this study is valid, highly reliable and fair. Hence, this test is of good quality, validated, reliable and can now be used in assessing students' specific learning strengths and weaknesses in secondary economics. It is an instrument that can measure the desired trait of secondary school economics in Nigeria, South Africa and other countries.

\section{Recommendations}

Based on the findings of this study, the researchers' recommend that the diagnostic economics test (DET) be used by the students to reinforce and improve their learning. Teachers should also be encouraged to use DET for identifying the least learned content areas of their students and to effect remediation promptly. School heads should use the DET as an evaluative tool for preparing the students for both internal and external examinations. School authorities should use the DET to monitor the teachers and their mastery of the subject as well as their coverage of syllabus. The DET should be adopted by government and used in all secondary schools as a tool to identify students' specific mastered and least learned content areas in (theory of demand, theory of cost/revenue and market structure) economics while teaching the students. The researchers finally recommend the instrument for use by future researchers interested in developing diagnostic tests. Similar test needs to be developed in other African countries including other countries of the world using specific country-based content areas.

\section{References}

Adu, E.O., Ojelabi, S.A., \& Hammed, A. (2009). Quantitative ability as correlates of students' academic achievement in secondary school economics. An international multi-disciplinary journal Ethiopia, 3(2), 322-333.

Alderson, J.C. (2005). Diagnosing foreign language proficiency: The interface between learning and assessment. London: Continuum.

Anyaele, J.U. (2003). Comprehensive economics for senior secondary schools. Kwara: A. Johnson Publishers Limited.

Anyanwuocha, R. A. I. (2006). Fundamentals of economics for senior secondary schools. Owerri: Africana First Publishers Limited.

Author \& Collaborator, (2010). Construction and validation of achievement test in senior secondary school economics. International Journal of Educational Research and Development, 4(1), 68-79.

Azizian, M., \& Abedi, M.R. (2006). Construction and standardization of reading level diagnostic test for third grade primary school children. Iranian Journal of Psychiatry and Clinical Psychology, 11(4), 379-387.

Betts, J.R., Hahn, Y., \& Zau, A.C. (2011). Does diagnostic math testing improve student learning? California: Public policy Institute (PPIC).

Ceniza, J.C., \& Cereno, D.C. (2012). Development of mathematic diagnostic test for DORSHS. Retrieved from http://www.doscst.edu.ph/index.ph[/academics/graduateschool/publication/category/5-volum-1-issue-1-2012?

Chandrasegaran, A.L., Treagust, D.F., \& Mocerino, M. (2007). The development of a two-tier multiple-choice diagnostic instrument for evaluating secondary school students' ability to describe and explain chemical reaction using multiple levels of representation. Chemistry Education Research and Practice, 8(3), 293-307.

Chudi, O.C. (2013). Economics - causes and remedies of student's poor performance: A case study of Afikpo north local government area. Retrieved 2 December 2014 from http://www.doublegist.com/economics-remedies-students-poor-performance/

Fourie, A., \& Krugell, W. (2015). Determining the economic literacy of introductory economic students in South Africa. International Journal of economic education and development, 6(1), 86-96.

Ihekwaba, C.N. (2002). Development and validation of a diagnostic physics test. $\mathrm{PhD}$ dissertation. Owerri: Imo State University, Nigeria.

Izard, J. (2005). Quantitative research methods in educational planning. Overview of test construction. Paris, France: International Institute for educational planning/UNESCO.

Kato, K. (2009). Improving efficiency of cognitive diagnosis by using diagnostic items and adaptive testing. (Doctoral

Dissertation).

101
Retrieved

from 
http://conservancy.umn.edu/bitstream/57169/1/Kato_umn_0130E_10759.pdf

Onunkwo, G.I.N. (2002). Fundamentals of educational measurement and evaluation. Owerri: Cape Publishers International Ltd.

Patel, R.N. (2012). Construction and try-out of science diagnostic test for the trainees of primary teachers college. International indexed and referred research Journal, 3(31), 18-19.

Richards, B.J. (2008). Formative assessment in teacher education: The development of a diagnostic language test for trainee teachers of German. British Journal of Educational Studies, 56(2), 184-204. http://dx.doi.org/10.1111/j.1467-8527.00403.x

Rivera, J.E. (2007). Test construction and validation: Developing a statewide assessment for agricultural science education. PhD dissertation. Retrieved 2 December 2014 from: /space.Library.Cornell.ed13/3496/1/9-10-06.pdf

South African National Senior Certificate Examination (2015). Diagnostic report on learner-performance. Department of Basic Education: 1-300.

Van der Berg, S., \& Louw, M. (2006). Lessons learnt from SACMEQII: South African students' performance in regional context. Stellenbosch: Stellenbosch University, Department of economics.

Winarni, I. (2002). The development of a diagnostic reading test of English for the students of medical faculty. Malang: Brawijaya University.

West African Examination Council (WAEC), (2012). Chief examiners' report. Retrieved from Weaconline.org.ng/e-learning-/Economics/econs22/Nw.html

West African Examination Council (WAEC), (2010). Chief examiners' report. Retrieved from https://lifemagnanimous.files.wordpress.com/2013/06/chief-examiners-report-report-for-the-dec-2010-lshsce.pd $\mathrm{f}$

\section{Figure 1: FINAL VERSION OF DIAGNOSTIC ECONOMICS TEST FOR SECONDARY SCHOOLS}

\section{A. Theory of Demand}

1. An effective demand is defined as

a) need backed up with the necessary ability but without the willingness to pay

b) desire that is not backed up by the required money to pay for it

c) want backed up with the desire and willingness to pay at a particular time.

d) goods required at a price and with the willingness to pay at a particular time.

2. A demand schedule is described as a table containing

a) the price and quantity of a commodity at a time

b) the relationship between price and quantity demanded of a commodity

c) the relationship between price and quantity supplied of a commodity

d) the quantity of goods the consumer is willing to buy.

3. The type of demand that exist between torch light and battery is known as demand.
a) competitive
b) complimentary
c) comprehensive
d) composite

4. What type of demand is a commodity that serves two or more purposes?
a) Complimentary
b) Competitive
c) Comprehensive 
d) Composite

5. The responsiveness of demand to a change in income is the measurement of demand.
a) perfect income
b) cross
c) income
d) price index

6. What type of price elasticity of demand is the diagram below representing?

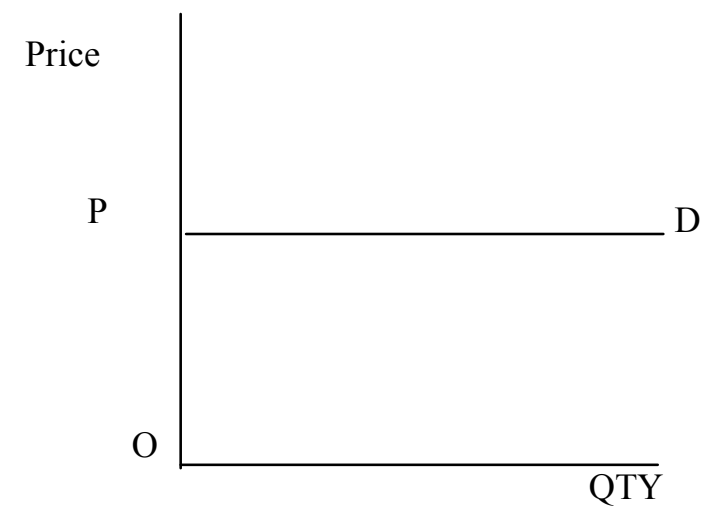
a) Perfect inelastic demand
b) Perfect elastic demand
c) Fairly inelastic demand
d) Unitary elasticity.

7. The income elasticity of a normal good is
a) Positive
b) negative
c) zero
(d) unitary.

8. Cross elasticity of demand refers to the degree of responsiveness of demand for a commodity to

a) changes in income of the consumers

b) changes in price of goods supplied

c) changes in the price of commodity

d) changes in the price of another commodity

9. Abnormal demand curves slope
a) downward from left to right
b) upwards from left to right
c) downwards from left to right
d) upwards from the origin.

10. A demand curve will shift to the left if
a) demand increases
b) demand decreases
c) demand stay the same
d) all of the above

11. A normal demand curve is best explained as being
a) concave to the point of origin
b) convex to the point of origin 
c) parallel to $\mathrm{X}$-axis

d) parallel to $Y$ - axis

12. Which of the following is an example of derived demand?
a) Demand for wood
b) Demand for floor
c) Demand for oil
d) None of the above

13. Change in the quantity demanded can be caused by
a) price of the commodity
b) price of other commodities
c) taste and fashion
d) weather condition

14. The diagram above illustrates elastic demand.
a) zero
b) infinitely
c) unitary
d) fairly
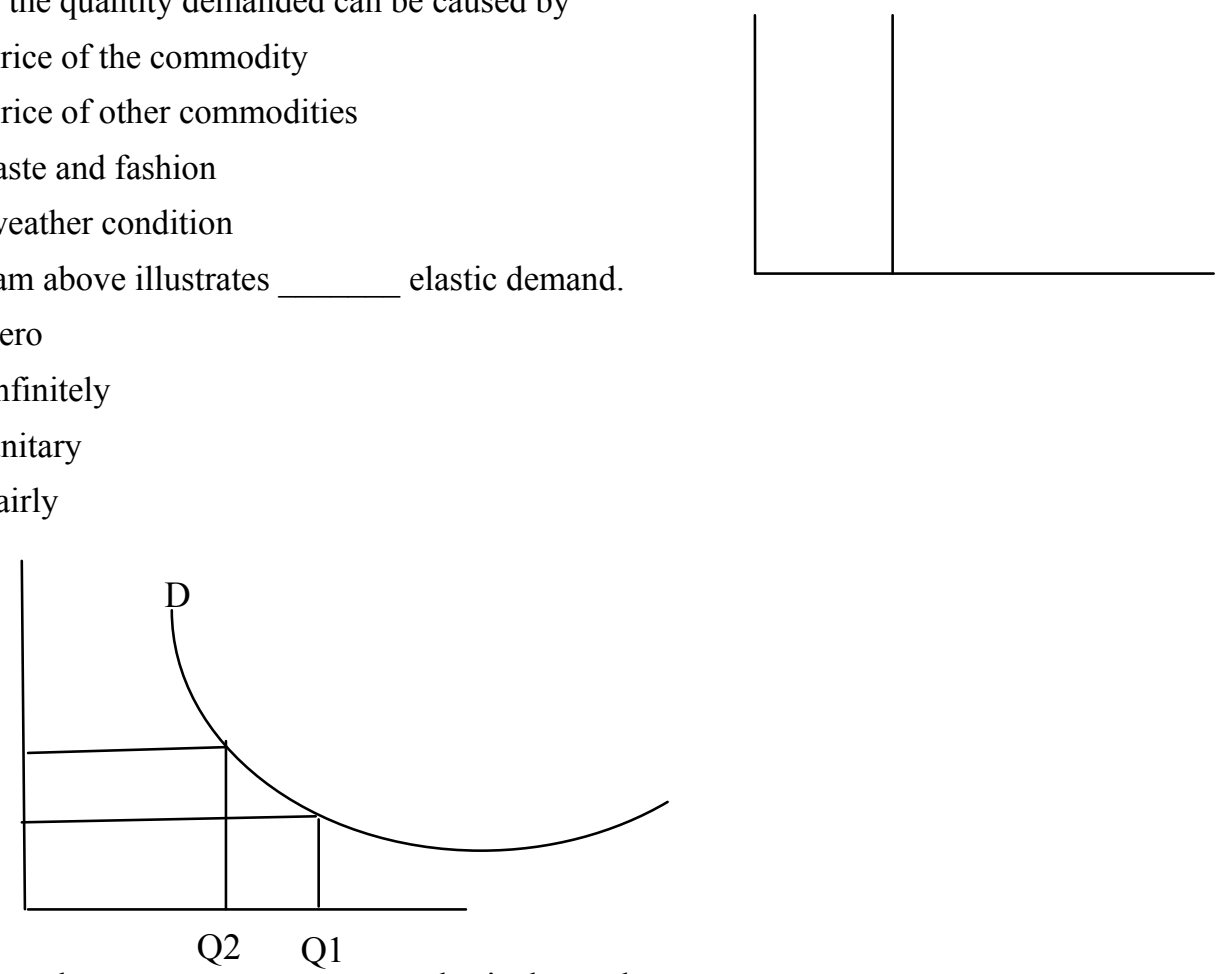

15. The diagram above portrays elastic demand.
a) infinitely
b) unitary
c) perfectly
d) fairly

The demand for beans is given by the function $\mathrm{Q}=36+0.4 \mathrm{P}$. When $\mathrm{P}$ is price in naira and $\mathrm{Q}$ is quantity. Use the above equation to answer question 16 and 17.

16. Find Q when $P$ is 20 naira $\quad$ (a) 44 (b) 54 (c) 34 (d) 64

$\begin{array}{llll}\text { 17. Find } Q \text { when } P \text { is } 50 \text { kobo } & \text { (a) } 36.2 \text { (b) } 3.63 \text { (c) } 32.6 & \text { (d) } 26.3\end{array}$

Given that quantity per period is a function of price and that the relationship is expressed as $Q=60-1 / 3 \mathrm{P}$,

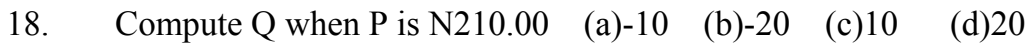

19. Compute Q when P is N0.00 (a)60 (b)50 (c)210 (d)20

Use the following demand schedule to answer questions 20-23.

\begin{tabular}{|l|l|}
\hline Price $(\mathrm{N})$ & Quantity demanded \\
\hline 15 & 60 \\
\hline 13 & 70 \\
\hline
\end{tabular}

20. Find the percentage change in demand 

a) $\quad 12.7 \%$
b) $\quad 15.7 \%$
c) $16.7 \%$
d) $\quad 19.7 \%$

21. Solve for percentage change in price
a) $\quad 13.3 \%$
b) $14.3 \%$
c) $15.3 \%$
d) $\quad 16.3 \%$

22. Using the result in questions 20 and 21 , derive co-efficient of price elasticity of demand
a) 0.3
b) 1.3
c) -1.3
d) 2

23. The co-efficient of price elasticity above can be interpreted as
a) inelastic demand
b) elastic demand
c) zero elastic
d) unitary elastic demand

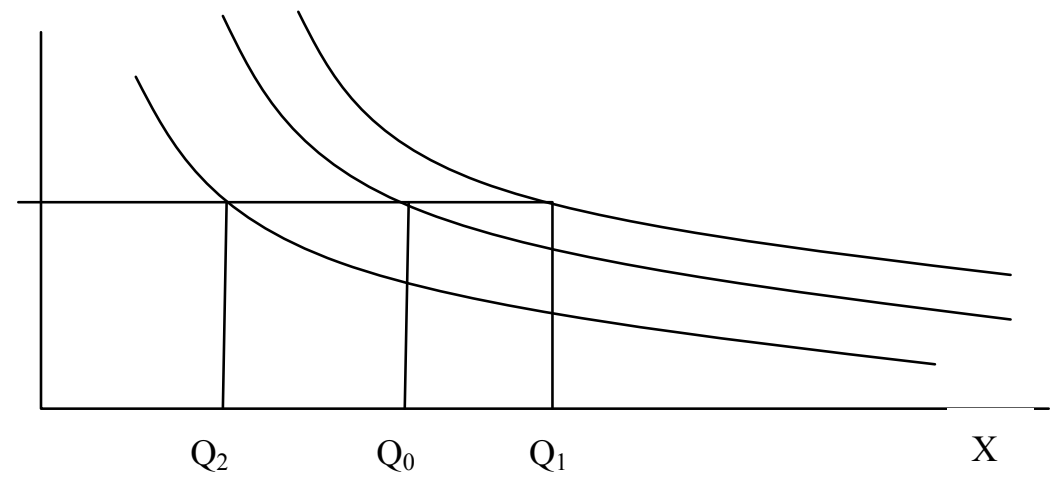

24. The diagram above shows
a. a shift in demand
b. a change in demand
c. a movement along demand curve
d. an abnormal demand curve

25. Abnormal demand curve occurs as a result of
a. articles of ostentation
b. giffen goods
c. rare commodities
d. all of the above

26. Demand schedule can be classified into categories
a) 2
b) 4 
c) 3

d) 5

27. Which of the following is NOT a type of demand?
a. Complementary
b. Competitive
c. Comprehensive
d. Composite

28. In a situation, where price elasticity of demand is unitary, a fall in the price of commodity will result in in demand.
a) an equal change
b) an increase
c) a decrease
d) a movement

29. Which of the following is not a type of price elasticity of demand?
a) Unitary
b) Zero
c) Infinitely
d) Positive

30. Which of the following is a type of income elasticity of demand?
a) Zero
b) Unitary
c) Infinitely
d) Negative

31. Which of the following affects elasticity of demand?
a) One's habit
b) Price system
c) Period of time
d) Wants

32. Which of the following factors does not cause a change in demand?
a) Taste and fashion
b) Weather condition
c) Price of other commodities
d) Price of the commodity

32. Which of these causes demand curve to shift to the right?
a) Decrease in the size of population
b) Increase in income of the buyer
c) Availability of substitutes
d) Increase in price of goods

34. Demand laws are divided into categories
a) 2
(b) 4
(c) 3
(d) 5

\section{B. Theory of Cost/Revenue}


1. Fixed costs are described as

a) the fixed price of producing a unit of output

b) various costs incurred in producing goods and services

c) costs of resources which do not vary with the level of output

d) costs of resources which vary with the level of output

2. What is the name of cost incurred by using both fixed and variable factors in production?
(a) Marginal output
(b) fixed cost
(c) total cost (d) average cost

3. In determining costs, accountants consider
a) implicit costs only
b) implicit and explicit costs only
c) explicit costs less implicit costs
d) none of the above

4. Opportunity cost is known as cost.
a) long run
b) short run
c) real
d) implicit

5. Revenue is best defined as
a) cost of goods multiplied by the quantity sold
b) price of goods multiplied by the quantity sold
c) quantity of goods plus purchase price
d) quantity supplied less quantity sold

6. Which of the following is an example of fixed price?
a) Expenditure on raw material
b) Expenditure on fuel
c) Expenditure on power
d) Rent on land

7. Which of this best summarized total fixed cost (TFC)?
a) $\quad \mathrm{TFC}=\mathrm{AFC} X$ Quantity produced
b) $\quad \mathrm{TFC}=\mathrm{ATC} X$ Quantity produced
c) $\quad \mathrm{TFC}=\mathrm{AVC} X$ Quantity produced
d) $\quad$ TFC $=$ TC $X$ Fixed cost

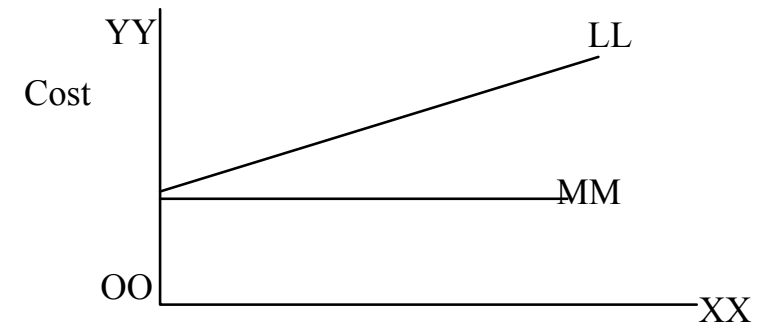

8. In the diagram above, the line $\mathrm{L}$ represents
a) total cost
b) variable cost 
average cost
d) fixed cost

9. A firm's short run is a period in which

a) at least two factors of production varies

b) at least one factor of production is fixed

c) all the capitals of production are running

d) all the money and opportunity cost of production vary

10. Which of these illustrates average revenue?
a) ATR X Q
c) TR- MR
b) $\quad \mathrm{ATR} / \mathrm{Q}$
d) $T R / Q$

Given that fixed cost is N500.00, variable cost is N1, 500.00 and output is 50 units.

11. Find the cost of producing one unit
(a) $\mathrm{N} 2.00$
(b) N60.00
(c) $\mathrm{N} 50.000$ (d) $\mathrm{N} 40.000$

12. Calculate for TC (a) N500.00 (b)N200.00 (c)N5000.00 (d) 600.00

$\begin{array}{cllll}\text { Output } & \text { TR }(\mathbf{N}) & \text { MR (N) } & \text { TC (N) } & \text { MC (N) } \\ 0 & 0 & - & 50 & - \\ 1 & 90 & 90 & 80 & 30 \\ 2 & 180 & 90 & 160 & (\mathrm{~T}) \\ 3 & 240 & 60 & 210 & 50 \\ 4 & 280 & (\mathrm{Q}) & 250 & 40 \\ 5 & 300 & 20 & 250 & (\mathrm{U}) \\ 6 & (\mathrm{P}) & 10 & 250 & 0 \\ 7 & 280 & -30 & (\mathrm{~S}) & 10 \\ 8 & 240 & (\mathrm{R}) & 240 & -20\end{array}$

Compute the missing figures $\mathrm{P}, \mathrm{Q}, \mathrm{R}, \mathrm{S}, \mathrm{T}$, and $\mathrm{U}$
13. $\mathrm{P}=$
$\begin{array}{lll}\text { (a) } 300 & \text { (b) } 280\end{array}$
(c) 310
(d) 210
14. $\mathrm{Q}=(\mathrm{a}) 60$
(b) 30
(c) 40
(d) 50
15. $\mathrm{R}=$
(a) -60
(b) 40
(c) -40
(d) 60
16. $\mathrm{S}=$
(a) 240
(b) 250
(c) 260
(d) 250
17. $\mathrm{T}=$
(a) 30
(b) 90
(c) 80
(d) 50
18. $\mathrm{U}=$ (a) 20
(b) -0
(c) 0
(d) -10

19. The idea of short-run and long-run period is required for grouping costs into
a) fixed and variable cost
b)money and opportunity costs
c) average and total costs
d)capital and running costs

20. Given that TR is total revenue, then TRn-TR(n-1) can be used to find the
a) marginal revenue
b)marginal cost
c) average cost
d)average revenue

Use the table below to answer question 55

Output Total Revenue (N) 


\begin{tabular}{ll}
\hline 1 & 40 \\
2 & 49 \\
3 & 56 \\
4 & 61 \\
5 & 65
\end{tabular}

21. The marginal revenue when output is 4 units is
(a)
N5.00 (b) N8.00
(c) N56.00
(d) N61.00

22. The shape of the average cost (AC) curve is a prove that as production increases

a) total cost decreases

b) average cost decreases and then increases

c) average cost increases and stop

d) total cost remains constant

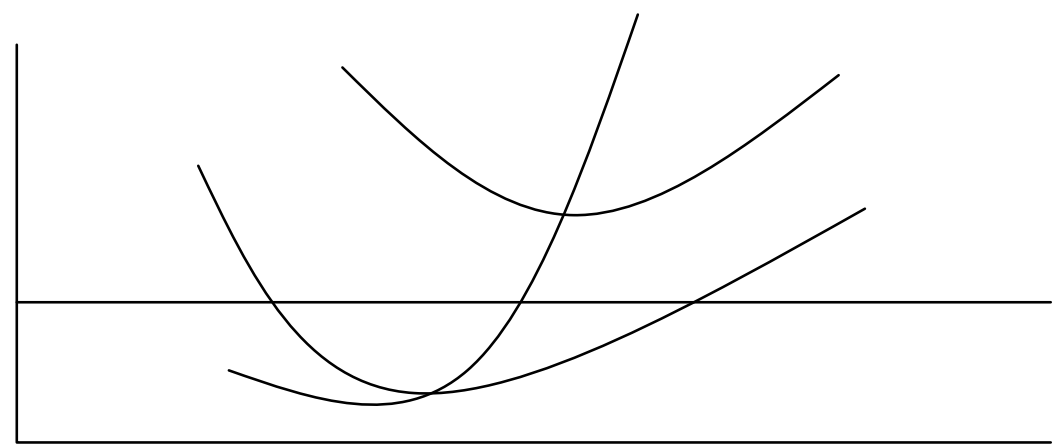

23. Which of the curves in the diagram above illustrates the firm's marginal cost (MC)?
a) Curve $P$
b) Cure $\mathrm{M}$
c) Curve $\mathrm{N}$
d) Curve L

24. Economists speak about opportunity cost when a consumer
a) has the chance to minimize cost
b) can equate his fixed costs with his variable costs
c) has forgo one thing in order to have another
a) is able to save part of his income

25. Which of the following constitutes the profit of the production?
a) total cost less total revenue
b) average revenue less average cost
c) total revenue less total cost
d) marginal revenue less marginal cost

\section{Market Structure}

1. What is the name of the market in which a single price obtains for a product?
a) Product market
b) Capital price market
c) Perfect market
d) Imperfect market 
2. Which of the following is a condition necessary for a perfect market?
a) The goods are heterogeneous
b) There is preferential treatment
c) There is a large number of buyers and sellers
d) Buyers and sellers are easily influenced

3. In a perfect market, price and quantity to be bought are determined by the
a) consumers and retailers
b) producers and wholesalers
c) forces of demand and supply
d) interest of Government and producers

4. Monopoly market can best be described as that which a single
a) seller sells a product which has no close substitute
b) buyer buys a product which has no close substitute
c) seller sells a product which has close substitute
d) buyer buys a product which has close substitute

5. The monopolists power can be controlled by
a) reduction of tariffs
b) privatization of companies
c) discouragement of merging
d) all of the above

6. The profit maximizing output of both monopolists and the perfect competitive firm occurs at the point where the marginal
a) cost curve cuts the marginal revenue curve from below
b) revenue curve intersects the $\mathrm{x}$ - axis from the top
c) revenue curve cuts the marginal output curve from top
d) costs cure intersects the $\mathrm{x}$ - axis from the below

7. A market with a large number of firms selling closely but differentiated products is known as market.
a) monopolistic
(b) monopoly
b) perfect
(d) imperfect

8. In the money market, money can only be borrowed for
a) long term
b) short term
c) capital project
d) public utilities

9. Which of the following is a type of monopoly?
a) Natural monopoly
b) Consumer choice monopoly
c) Output monopoly
d) Exertion monopoly 


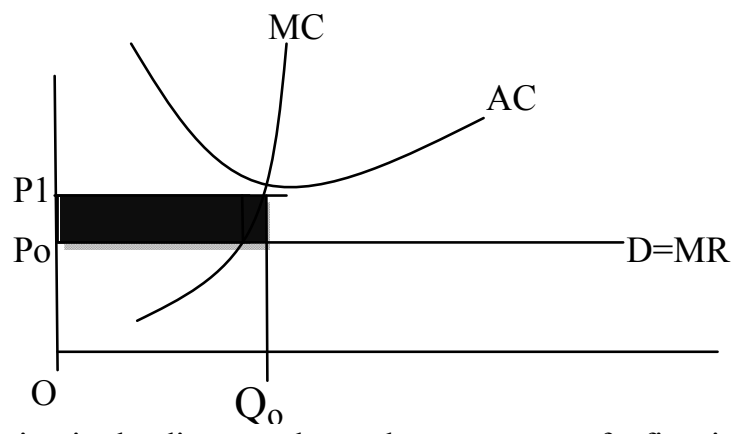

10. The shaded portion in the diagram above shows of a firm in a perfect market.
a) short- run profit
b) short- run loss
c) long- run profit
d) long- run loss

11. Which of the following market structure is an example of an imperfect market?
a) Money Market
b) Capital market
c) Monopoly market
d) Factor market

12. Which of the following is a disadvantage of monopoly market?
a) It discourages invention
b) Expansion is not possible
c) Suppliers bear the brunt
d) It cause unemployment

13. Which of the following is true of a stock exchange market?
a) Exchange of commodities
b) Purchase and sale of securities
c) Exchange treasury bill for bills of exchange
d) Sells and buys foreign exchange

14. Which of the following is a feature of market economy?
a) Free competition among economic units
b) Firms are motivated by profit
c) Resources are effectively allocated
d) All of the above

15. Which of the following is applicable in a perfect market?
a) $\quad \mathrm{P}=\mathrm{MR}>\mathrm{AR}$
b) $\quad \mathrm{MP}=\mathrm{MC}>\mathrm{P}$
c) $\quad \mathrm{P}=\mathrm{MR}=\mathrm{MC}$
d) $\quad \mathrm{P}=\mathrm{MR}<\mathrm{PM}$

16. Which of the following is used by the government to control monopolist power?
a) Labour Union
b) b) Price Legislation
c) c) Import restriction 

d)
d) Export Promotion

17. A monopolistic market situation exists where
a) there is no pure monopoly
b) there is homogeneity of products
c) there is heterogeneity of products
d) all of the above

18. Which of the following causes monopoly?
a) Homogenous goods
b) Adequate information of the goods
c) Free Movement of Resources
d) None of the above

19. Advertising expenses would not be necessary under perfect competition because
a) consumers would have complete knowledge of goods and services
b) cost of production would be at the maximum level
c) every firm would enjoy the benefits of large scale production
d) income of the consumers of the commodity would be high

20. Which of the following is true of a monopolist average revenue curve (AR)?
a) It is above the total cost curve
b) It is the same as the marginal cost curve
c) It is above the marginal revenue curve
d) It is the same as that of the perfect competitor

21. Monopoly is important in an economy because
a) it reduces tariffs
b) it discourages merging
c) it prevents over-production
d) it cause unemployment

22. Which of the following does a foreign exchange market deal with?
a) Treasury bills (b)
(b) Currencies (c)
(c) Government bonds
(d)Commodities

23. Monopolistic and perfect competition are similar in that
a) there is free entry into and exit from both markets
b) both makes less profit in the short run
c) both increases the cost of goods
d) there is over production and wastages in both market

24. The following are conditions for a perfect market EXCEPT that
a) there are many buyers and few sellers
b) commodities bought and sold are homogenous
c) there is free movement of resources
d) the same market ruling price exist 